\title{
Correlation between Ecological Civilization Construction and Financial Agglomeration in Guizhou
}

\author{
Hongmei Zhang ${ }^{1,2,3}$ Ning Zhang ${ }^{1,2,3}$ Yingpeng Lai $^{4}$ \\ ${ }^{1}$ Guizhou University of Finance and Economics, Institute of Finance \\ ${ }^{2}$ Guizhou Institution for Technology Innovation \& Entrepreneurship Investment \\ ${ }^{3}$ Guizhou Institute of Urban Economics and Development Guiyang Guizhou 550025, \\ China
}

\begin{abstract}
With the rapid economic development and overall social reform, it is particularly important to correctly handle the relationship between the construction of ecological civilization and financial accumulation. At present, most of the studies on financial agglomeration are all integrated with the development of regional economy, industrial structure and urbanization, but relatively few are combined with the construction of ecological civilization. The main starting point of this article is to put the two together, hoping to find the relevance of the two. The Location Entropy Method Used for Measuring the Degree of Financial Agglomeration. Through empirical analysis, it expanded the research ideas and built the evaluation index of ecological civilization construction and financial agglomeration. The results show that there is a certain correlation between ecological civilization construction and financial agglomeration in Guizhou Province.
\end{abstract}

Keywords

Ecological civilization; Financial agglomeration; Location entropy; Green finance

\section{贵州省生态文明建设与金融集聚相关性 研究}

\author{
张红梅 $1,2,3$ 张宁 $1,2,3$ 赖应鹏 4 \\ 1贵州财经大学, 金融学院 \\ 2贵州科技创新创业投资研究院 \\ 3 贵州城镇经济与发展研究院, 贵州, 贵阳 550025 \\ ${ }^{4}$ 中国农业银行贵州省分行
}

\begin{abstract}
摘要：伴随着经济的的快速发展和社会的全面改革，正确的处理协调好生态文明建设和金融 集聚两者之间的关系变得尤为重要。当前大部分金融集聚的研究都是与区域经济发展、产业 结构和城镇化等相结合, 而与生态文明建设的结合相对的较少。本文主要的出发点是将两者 放在一起，希望找出两者的相关性。对金融集聚程度的测度采用的区位熵方法。通过实证分
\end{abstract}


析, 拓展了研究思路, 构建了生态文明建设与金融集聚评价指数。结果表明, 贵州省的生态 文明建设与金融集聚之间存在着一定的相关性。

关键词：生态文明; 金融集聚; 区位熵; 绿色金融

\section{1. 引言}

在西部经济的发展过程中，国家 给于西部地区以政策和资金的支持, 西部地区的经济得到快速发展。同时 随着金融机构的加入，西部的金融行 业开始出现了集聚的现象。基于西部 金融行业的集聚使得当地的生态发生 怎么样的变化和生态文明建设程度是 否可以吸引更多的金融行业的进入, 研究两者之间的相关性便应运而生。 通过两者间相关性的研究, 有利于贵 州省相关政策的制定，对于贵州省生 态文明建设和金融集聚的均衡协调发 展具有重大的意义。

\section{2. 相关概念的概述}

\section{1. 生态文明的内涵}

生态文明是指人类遵循客观规律 （人与自然、人与人、人与社会和谐 相处) 、保护和建设生态环境而取得 的成果。生态文明属于我国特色社会 主义的本质特征和内在要求, 是一种 1

倡导低碳环保的一种生产生活方 式, 区别于原来的工业文明, 是在工 业文明基础的一次超越。当前我国很 多地区面临着环境污染、资源枯竭的 情况, 因此我们必须树立尊重自然、 顺应自然、保护自然的生态文明建设 理念。党的十八大提出将生态文明加

基金项目: 本文由贵州省科技计划项目 （黔科合基础 [2016]1534-4 号) 资助。项 目名称: 贵州新型城镇化金融支持效率研 究。
入到五位一体的总体布局中，首次把 生态文明建设加入到党章中, 充分体 现了经济和生态协调的重要性。

国家的西部大开发政策推行以 来, 使得西部地区的经济得到快色的 发展, 但是不可避免的导致了生态环 境的毁坏。当前整个西部地区生态环 境总体都处于恶化状态，局部地区稍 微得到改善。因此西部地区以后发展 经济的过程中必须遵循国家的五位一 体总体布局的政策推进生态文明的建 设, 大力发展新兴产业, 走新型的可 持续发展的道路。

\section{2. 金融集聚的内涵}

集聚主要是在一定的空间或者地 域内一个行业或者一些企业因具有独 特的优势而集中在一起来相互促进相 互发展。金融作为我国经济发展的一 个重要的邻域, 伴随着经济的快速的 发展和市场自由化程度的加深, 金融 集聚的现象逐渐产生。金融集聚是指 金融行业中的一些部门或者企业等具 有总部功能的机构在某一地区形成集 中的趋势, 并与其他国际性机构之间 存在密切往来联系的一种产业空间结 构。当前金融集聚的模式主要存在两 种情况: 一种是以市场作为主导, 另 一种是以政府作为主导。市场主导的 大部分都是在经济比较发达并且金融 行业比较多的地方自发形成的集聚现 象; 而政府主导是在经济处于经济发 展进程缓慢并且金融行业较少的情况 下, 由政府实施一些优惠的政策和措 施等人为的推动金融集聚的形成。 


\section{3. 贵州省金融集聚程度}

对于一个行业的集聚程度的检测 的方法主要有：（1）行业集中度。

（2）区位熵。（3）赫芬达尔-赫希曼 指数。（4）产业聚集指数。（5）空 间集聚指数。其中的区位熵操作简 单, 对于指标的选取相对明确, 是一 种最为普遍的一种计算集聚程度的方 法。因此，我们也是用区位熵来计算 贵州省近几年的金融行业的集聚程 度。

\section{1. 区位熵简介}

区位熵也称为行业的地区集中度 指标或者专门化率, 是一个地区行业 的比率与全国的行业的比率, 是一种 较为普遍的集聚识别方法。区位摘可 以用来衡量一个产业在一个地区的集 中程度, 主要是用来显示所考察行业 的专业化程度, 以及该行业在该地区 的地位和作用等。区位摘不仅可以分 析一个地区某个行业在全国中的优势 情况, 而且还可以根据区位熵的大小 来衡量这个行业的发展状况，一般来 说, 数值越大, 说明该行业在全国中 所占的优势较大并且发展的状况也相 对较好。

在实践中, 可以选择就业人数、 企业数量、生产总值、生产增加值或 者销售总收入等指标来分别计算不同 行业的集聚程度。区位熵的计算公式 如下:

$$
L Q_{a b}=\frac{q_{a b} / q_{b}}{q_{a} / q} \quad L Q_{a s}=\frac{\sum_{a b} / \sum_{b=1}^{m} q_{a b}}{\sum_{a=1}^{n} q_{a b} / \sum_{a=1}^{n} \sum_{b=1}^{m} q_{a b}}
$$

上面的两个公式都可以作为区位 熵的计算公式, 在公式中, $L Q_{a b}$ 就是 $\mathrm{b}$ 地区中的 $\mathrm{a}$ 行业在全国的区位摘, $q_{a b}$ 为 $\mathrm{b}$ 地区的 $\mathrm{a}$ 行业的相关指标;

$q_{b}$ 为 $\mathrm{b}$ 地区所有行业的相关指标; $q_{a}$ 指在全国范围内 $\mathrm{a}$ 行业的相关指标; $\mathrm{q}$ 为全国所有行业的相关指标。 $L Q_{a b}$ 的 值越大, 说明该地区行业集聚的程度 越高, 一般来说: 当 $L Q_{a b}>1$ 时, 我 们就认为 $\mathrm{b}$ 地区的 $\mathrm{a}$ 行业的发展水平 高于全国同类行业的平均水平并且全 国中具有一定优势; 当 $L Q_{a b}<1$ 时, 我们就认为 $\mathrm{b}$ 地区的 $\mathrm{a}$ 行业的发展水 平低于全国同类行业的平均水平并且 在全国中具有劣势。

为了保证区位熵算法的准确性, 本文选取了《中国统计年鉴》和《贵 州统计年鉴》中 2008 年-2015 年公布 的全国和贵州的所有产业的生产总值 与金融生产总值，以确保数据的权威 性。

表 1 贵州省区位熵计算结果

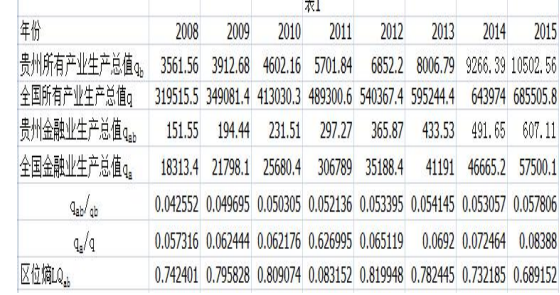

由上面的贵州省区位熵表，可以 看出贵州省区位熵 $L Q_{a b}$ 均小于 1 , 说 明贵州省的金融业集聚的程度不高, 金融行业的发展水平低于全国金融行 业的平均水平, 在全国的金融行业中 处劣势的地位。

\section{2. 金融集聚水平提高策略}

(1) 国家在大力开展西部大开发的 过程中, 要做好金融资源空间布局, 大力推进金融立法工作和金融监管制 度体系，既要保证整个金融业的平稳 
运行，也要控制西部地区各种金融风 险的发生。同时要出台相关金融的优 惠政策，把东中部与西部相结合发 展。鼓励大型金融机构的积极的向西 部地区进行业务的拓展，从而实现金 融业区域的协调发展。

(2) 贵州省本地区一个方面要加强 高层次金融人才的培养和锻炼。现在 处于金融行业发展的快速时期，金融 人才就成为了金融集聚的主要的动力 之一。因此贵州省要创造优良的金融 氛围, 利用高的工资来吸引各种金融 人才的入驻; 要加强本地区学生的金 融学习能力, 对于优秀的学生可以采 取有效的培训的措施、开设人才培养 班或者可以去东部进行培训, 致力于 培养全能金融人才。同时, 贵州省业 鼓励和组织有条件的地区的金融机构 集聚发展，发挥金融机构之间的总体 功能, 为企业、个体户和百姓提供便 利。

（3）贵州省要学会建立多层次的金 融市场体系, 提升金融创新能力和水 平，全方位加大市场的融资力度; 发 展壮大各种金融机构, 建立更加完善 和层次分明的金融行业体系。面对当 前互联网的快速发展，金融行业也可 以发展互联网金融, 加大第三方支付 对于金融行业的支持, 政府要积极引 导各大金融机构与互联网的合作，完 善互联网金融体系, 加快传统金融行 业的创新力度, 紧跟当前国内大型金 融机构的步伐，从而推进贵州省的金 融发展水平，使金融集聚程度可以大 大提高。

\section{4. 生态文明与金融集聚的关系研究及 建议}

\section{1. 生态文明建设与金融集聚的相关性}

生态文明和金融集聚两者之间存 在着辩证统一的关系。唯物辩证法提
到：整个世界是一个普遍联系的整 体, 事物内部各个要素和事物之间是 相互影响、相互制约和相互作用的, 人们在认识事物的同时, 既要看到事 物区别又要看到事物的联系, 只有把 两者统一起来才能实现两者的和谐发 展。用辩证统一的观点看待生态文明 和金融集聚，它们之间便是相互作 用、相互影响。生态文明和金融集聚 两者之间是不可脱离的, 离开了生态 文明单独的发展金融和经济, 不仅不 会发展迅速，反而会使得长远目标无 法实现。同样, 离开了金融和经济的 生态文明, 整个社会将会停滞不前。 两者的关系具体来说是:

一方面, 生态文明建设是各个环 节基础。生态文明建设对于金融既具 有反馈作用, 高水平的生态文明建设 不仅有利于经济社会的发展, 而且能 够为金融向本地区集聚提供了前提条 件。相反, 低水平的生态文明建设只 会增加经济的负担, 致使本地的金融 难以发展起来, 进而阻碍了金融集 聚。

另一方面，生态文明的建设离不 开金融集聚的发展, 金融集聚为生态 文明建设提供了物质保障和动力。生 态文明的建设要依赖于金融集聚来发 挥作用, 金融集聚可以促进金融行业 的人才、资金和技术的加入，从而引 导地区的资源达到合理的规划使用、 促使产业结构的转变, 使得地区的生 产总值的增加。这样以来, 政府会加 大对环境污染治理的投资, 最终地区 的生态文明建设将得到加强。

当前人们只是强调对自然的利用 和改造, 这就造成了资源枯竭和环境 破坏, 这不仅仅影响到人类的生存环 境, 而且还影响到我国经济的可持续 发展。总的来说, 生态文明建设和金 融集聚不是对立和排斥的关系, 两者 的关系尤为密切, 因此我们要学会统 
筹兼顾，从而实现两者的之间共生发 展和协调。

\section{2. 贵州省生态文明建设与金融集聚的 相关性实证分析}

(1) VAR 模型

向量自回归模型简称为 VAR 模 型, 它主要是把每一个内生变量作为 所有内生变量的滞后值的函数来构造 的模型, 由双变量回归推广到多变量 回归。VAR 模型主要是通过实际的经济 数据而不是经济理论来确定的一种结 构, 在进行参数估计时比较的容易, 同时 VAR 模型可以任意添加其他的解 释变量, 还可以比较准确的预测短期 结果。也存在一部分缺点就是 VAR 模 型主要是应用于经济学领域, 并且在 运用的时候存在一定的局限性。VAR一 般的数学表达式如下:

$Y_{t}=c+A_{1} y_{t-1}+A_{2} y_{t-2}+\ldots \ldots+A_{p} y_{t-p}+u_{t}$

表达式中的 $\mathrm{c}$ 是 $\mathrm{n} \times 1$ 常数向量, $A_{i}$ 是 $\mathrm{n} \times \mathrm{n}$ 的矩阵。 $u_{t}$ 是 $\mathrm{n} \times 1$ 的误差 向量。

(2) 平稳性检验

我们知道在对一个时间序列进行 最终结果分析的时候, 一定先要对所 有的时间序列进行平稳性检验, 以避 免出现 “伪回归” 的现象。其中单位 根检验就是测度平稳性的一种方法。 如果我们观察到一个时间序列的均值 和协方差随着函数的时间的变化而变 化, 那么就是一个不平稳的时间序 列, 这就需要对时间序列进行取对 数，若取完对数之后的时间序列平 稳, 则称该序列为一阶单整序列, 否 则需要在对其取差分, 直至得到的时 间序列为平稳，但其中的差分的次数 不得超过时间的数量。
表2: 本位根检践结果

\begin{tabular}{|c|c|c|c|}
\hline 变量 & $4 D F-t$ & $A D F-p$ & 5Wlevel \\
\hline Log $(\mathrm{g}) \mathrm{P}$ & 0.302703 & 0.969 & -3.098896 \\
\hline $\mathrm{Log}_{-} \mathrm{H} T \mathrm{TZ}$ & -0.268736 & 0.9073 & -3.098896 \\
\hline Dif Log GDP & -3.473062 & 0.0292 & -3.144920 \\
\hline Dif Log $\mathrm{HJTZ}$ & -3.842868 & 0.0145 & -3.119910 \\
\hline
\end{tabular}

由表 2 的 $\mathrm{ADF}$ 检验的结果可以看 出, 贵州省的环境污染治理投资总额 和贵州省 GDP 原来的指标变量均是不 平稳的。对变量进行取对数后 $\mathrm{ADF}-\mathrm{p}$ 值明显大于 0.05 , 因此也呈现出不平 稳。只有在对其去差分之后, 两个变 量得到的 $A D F-p$ 值明显小于 0.05 , 并 且 $A D F-t$ 值小于在 $5 \%$ 水平下的数值, 因此贵州省的环境污染治理投资总额 和贵州省 GDP 指标均在 5\%显著性水平 下拒绝存在单位根的原假设, 接受备 择假设, 被检测变量均显示平稳, 所 以对原序列取对数后的序列是一阶单 整的。

(3) 格兰杰因果关系检验

格兰杰因果关系检验最主要的一 点是所研究的时间序列需要具有平稳 性的特征, 否则就会出现伪回归的现 象。但是格兰杰因果关系检验的缺点 就是结果只是统计意义上存在着因果 关系, 不是真实存在着因果关系, 当 然这一个缺点也不影响其参考价值。 格兰杰因果关系检验对于经济的发展 和预测还是有很大作用的。

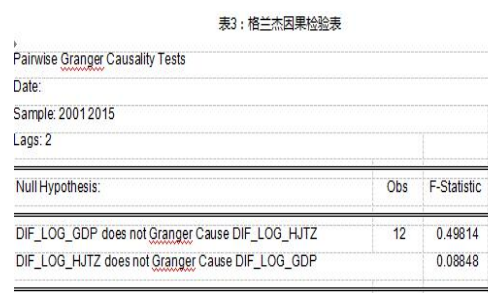

由上面的格兰杰因果关系检验 表, 可以得出, 格兰杰检验结果中的 两个 $\mathrm{p}$ 值均大于 0.05 。在 $5 \%$ 的显著水 
平下，拒绝 “贵州省 GDP 不是贵州省 的环境污染治理投资总额

变化原因”的原假设, 即贵州省 GDP 是贵州省的环境污染治理投资总额 变化原因的可能性达到 95\%以上。说明 在样本区间内两者是存在关系的, 由 于贵州省的 GDP 中包含着点三产业中 金融产业部分，生态文明建设中包含 着贵州省的环境污染治理投资总额， 所以两者之间存在着间接关系，具有 一定的相关性。

\section{3. 提高生态文明的策略}

本文的第二部分中提到的贵州省 的金融集聚水平相对处于劣势，这就 对贵州省的生态文明建设产生一定的 影响。实证分析中的环境投资总额的 数据虽然每年都处于增长, 但是投资 的数量还是较低并且增长的速度较 慢。因此提出以下的几点提高贵州省 生态文明的策略:

政策支持。当前经济的发展需求 我们加快生态文明的建设, 大力推动 第三产业的发展, 转化生产方式, 调 整产业结构, 发展循环模式经济, 从 而实现经济和环境发展的统一。党的 十八大也提出了中国梦的实现要以生 态文明的建设为目标, 因此贵州政府 要加强生态环境资源保护法的的建 设, 积极引导人们加入到保护环境和 节约资源的行列中来, 与人们进行积 极有效的沟通，才能实现政策和法律 法规的实施。

金融支持。金融是现在经济发展 的重要环节, 因此生态文明的建设需 要的金融的支持。贵州省要积极推进 绿色金融的发展, 绿色金融是以建设 绿色经济为导向, 以促进环境保护、 污染治理和经济与环境相协调为目 的, 以债券、股票及其他的金融工具 为手段, 从而促进社会的可持续发 展。绿色金融的发展要加强内外的激
励和监督机制, 金融监管部门要做好 全面的战略发展决策, 各个金融机构 之间要保持信息的畅通性, 加强与国 际和其他国家绿色金融部门的合作。

保护力度。加大自然生态系统和 保护环境的力度, 必须科学实施。要 逐步的推进生态系统的修复工程建 设, 加强环境检测水平, 建设本地区 防灾减灾体系。做到预防为主、综合 治理、源头治理和综合治理的方式。

\section{5. 结束语}

综上所述，本文通过对生态文明 建设和金融集聚的实证研究和分析得 出, 贵州省的金融集聚程度较低及生 态文明建设和金融集聚具有间接的相 关性。但是, 本文的研究存在较多的 不足之处, 在未来的研究中, 需要对 大量数据进行具体分析, 加强样本的 完整性与协调性, 为研究的实效性提 供基础保障。这是经济研究的根本目 的同时也是未来研究的方向。

\section{参考文献}

[1] 刘尚荣. 生态文明建设与金融支持 [J]. 青海金融, 2008, 6: 14-16.

[2] 王遥,张笑. 生态文明视域下的生 态金融建设 [J]. 中国特色社会主义 研究, 2005, 2 : 96-100.

[3] 白彩全,何宜庆. 省域金融集聚与 生态效率耦合协调发展研究 [J]. 干 旱区资源与环境, 2004, 28(9)：1-7.

[4] 马骏. 中国绿色金融的发展与前景 [J]. 经济社会体制比较, 2016, 6 : 25-32.

[5] 郭濂. 发挥开发性金融作用, 推动 生态文明建设 $\mathrm{N}]$. 中国经济导报, 2014-12-30(A03).

[6] 豆晓利. 中国金融产业集聚水平测 度 $[\mathrm{J}]$. 金融发展研究, 2012, 11 (12). 